\title{
DNA Extraction from Archived Paraffin Embedded Tissues: A Comparative Study Using Three Different Extraction Method-Extraction of DNA from Paraffin Embedded Tissues
}

\author{
Shruthi Suresh ${ }^{1}$, Kavitha B. ${ }^{2}$, Sivapathasundharam B. ${ }^{3}$ \\ ${ }^{1}$ Former Post Graduate Student, Department of Oral Pathology and Microbiology, Meenakshi Ammal Dental \\ College and Hospital, Chennai, Tamil Nadu, India, ${ }^{2}$ Professor, Department of Oral Pathology and Microbiology, \\ Meenakshi Ammal Dental College and Hospital, Chennai, ${ }^{3}$ Professor and Head, Department of Oral Pathology \\ and Microbiology, Meenakshi Ammal Dental College and Hospital, Chennai, Tamil Nadu, India
}

\begin{abstract}
Objective: Formalin fixed paraffin embedded (FFPE) tissue is a valuable source of nucleic acids required for various molecular studies. The purpose of the present study was to extract Deoxyribonucleic acid (DNA) from archival retrieved FFPE oral squamous cell carcinoma tissues using three different extraction method (salting out, commercial kit and microwave method) and to compare the yield of DNA extracted by these method.
\end{abstract}

Method and Material: 30 oral squamous cell carcinoma paraffin embedded tissue blocks were categorized into three groups based on the duration of storage as Group $\mathrm{A}(<2$ years $), \mathrm{B}(2-4$ years $)$ and $\mathrm{C}(4-6$ years $)$. The tissue sections made from these blocks were subjected to three DNA extraction method and the DNA yield was measured using a spectrophotometer. The extracted DNA was checked by successful amplification of p53 gene using Polymerase Chain Reaction followed by gel electrophoresis. The values of DNA yield and purity were statistically analysed and the level of significance was set at $P \leq 0.05$.

Results: The DNA yield was above $3 \mu \mathrm{g}$ in all the three extraction method. On multiple comparison, the mean DNA yield was statistically significant $(P$ value $<0.05)$ among the three method in Group A. Also, the DNA yield was found to be higher in salting out method though successful amplification was obtained from the extracted DNA in other extraction method as well.

Conclusions: DNA was successfully extracted from all the tissue samples using all the three method. Salting out method yielded the maximum amount of DNA compared to the other method and shall be a good cost effective alternative.

Keywords: DNA; Paraffin embedding; Polymerase Chain reaction; Oral squamous cell carcinoma.

\section{Introduction}

There are about a trillion cells in the human body containing the vital source for life, the Deoxy ribonucleic

\section{Corresponding Author:}

\section{Dr. Shruthi Suresh}

Former Post Graduate Student, Department of Oral

Pathology and Microbiology, Meenakshi Ammal Dental College and Hospital, Chennai, Tamil Nadu, India e-mail: drshruthis7@gmail.com acid (DNA) in their nucleus. Isolation of genomic DNA is the key step for numerous applications and molecular studies ranging from basic research to routine diagnostic and therapeutic decision-making. ${ }^{[1]}$ The extracted DNA is used to study alterations in the DNA sequence which is responsible for development and progression of various pathologic conditions. A wide variety of techniques have been employed to extract DNA from different sources such as body fluids, cell cultures, animal tissues (fresh, frozen or fixed) and microorganisms. ${ }^{[2]}$ The archived Formalin Fixed Paraffin embedded (FFPE) tissues are 
an excellent source for recovery and analysis of nucleic acids which has become an important tool for cancer research over the last decade. Fixation techniques, formation of protein cross links, storage condition and duration makes DNA extraction from FFPE tissues challenging. Hence the need arises to choose the best method of DNA extraction to obtain maximum yield of the purest form of DNA and that which can be amplified. The present study was aimed to extract DNA from archival retrieved paraffin embedded oral squamous cell carcinoma (OSCC) tissue blocks using Salting out method, Commercial kit method and Microwave method and to estimate and compare the extracted DNA quantitatively and qualitatively in all the three method using spectrophotometer and gel electrophoresis respectively. The assessment of successful DNA extraction from the three method was done by PCR amplification of $\mathrm{p} 53$ gene. ${ }^{[3]}$

\section{Materials and Method:}

A total of 30 archival retrieved tissue blocks previously confirmed histopathologically as oral squamous cell carcinoma were chosen for this in-vitro study. Ethical clearance for the study was obtained from the Institutional Review Board. The tissue blocks were categorized into three groups based on the duration of storage as Group A (10 blocks stored for duration of $<2$ years), Group B (10 blocks stored for duration of 2-4 years) and Group C (10 blocks stored for duration of 4-6 years). Ten sections of $10 \mu \mathrm{m}$ thickness were cut from each paraffin embedded tissue block. The sections were collected in a $2 \mathrm{~mL}$ micro centrifuge tube (Tarsons, Kolkata, India). The same numbers of sections were collected from each case, in three different tubes.

Deparaffinisation: $1 \mathrm{ml}$ preheated xylene was added to each micro centrifuge tube containing the sample. The tubes were incubated at $56^{\circ} \mathrm{C}$ for 10 minutes in a water bath for dissolution of paraffin and were centrifuged (REMI, Mumbai, India) at $10300 \mathrm{rpm}$ for 5 minutes. The supernatant was decanted without disturbing the pellet. A new change of preheated xylene was added. The steps were repeated until the paraffin was completely removed. ${ }^{[4]}$

Tissue Digestion: The pellet was washed in $100 \%$ ethanol $(500 \mu \mathrm{l})$ to remove any residual xylene. The cells in the tissue pellet were lysed using a homogenizer and then centrifuged at $10300 \mathrm{rpm}$ for 5 minutes. The pellet was washed in $95 \%$ ethanol $(500 \mu \mathrm{l})$ followed by $70 \%$ ethanol $(500 \mu \mathrm{l})$. The homogenization and centrifugation steps were repeated before and after the ethanol washes. $200-400 \mu 1$ of $250 \mu \mathrm{g} / \mu \mathrm{l}$ Proteinase K (MP Biomedicals, USA) containing digestion buffer was added to break the peptide bonds of proteins. The tissues were digested by incubating them at $55-60^{\circ} \mathrm{C}$ for 3-5 days in an orbital shaking incubator (REMI, India). $250 \mu \mathrm{g} / \mu \mathrm{l}$ proteinase $\mathrm{k}$ (working concentration) was replaced daily. Proteinase $\mathrm{K}$ was inactivated after adequate tissue digestion by heating at $95^{\circ} \mathrm{C}$ for 10 minutes as they might interfere with further analytical procedures. ${ }^{[4]}$

Salting Out Method: $200 \mu 1$ of Ammonium acetate (3.5M) solution was added to precipitate proteins as they are less soluble in high salt concentration. The tubes were vortexed using a cyclomixer (REMI, Mumbai, India) for 20 seconds and were incubated on ice for 5 minutes followed by centrifugation at $14300 \mathrm{rpm}$ for 3 minutes. The supernatant containing DNA was transferred to another tube. $600 \mu \mathrm{l}$ of Isopropanol was added to the supernatant in order to precipitate DNA. The samples were centrifuged at $16300 \mathrm{rpm}$ for 5 minutes. The DNA pellet was washed in $70 \%$ ethanol $(500 \mu \mathrm{l})$ to remove any residual salt attached to the DNA. The tubes were centrifuged at $16300 \mathrm{rpm}$ for 2 minutes. The supernatant was discarded and the remaining ethanol was allowed to evaporate. DNA was dissolved in $30-50 \mu 1$ of TE (Tris EDTA) solution. Extracted DNA was stored at $4^{\circ} \mathrm{C}$. ${ }^{[4]}$

Commercial Kit Method: The commercial QIAamp DNA Mini Kit (Qiagen, Gmbh, Germany) was used according to the manufacturer's protocol. The dewaxed tissues were digested with $180 \mu 1$ ATL (Animal Tissue Lysis) buffer and homogenized. Tissue lysis was carried by incubating the tubes at $56^{\circ} \mathrm{C}$ for $1-3 \mathrm{hrs}$ with Proteinase K $(20 \mu \mathrm{l})$ until complete tissue lysis. Buffer AL $(200 \mu \mathrm{l})$ was added. Pulse vortexing for 15 seconds was done and incubated at $70^{\circ} \mathrm{C}$ for 10 minutes. 200 $\mu \mathrm{l}$ Ethanol (96-100\%) was added and vortexed. The solution was transferred into a spin column, centrifuged for one minute at $8000 \mathrm{rpm}$, and washed with AW1 and AW2 buffers. DNA was eluted by 1 minute incubation at room temperature with $50 \mu \mathrm{l}$ elution buffer $\mathrm{AE}$ and was collected by centrifugation at $8000 \mathrm{rpm}$ for 1 minute. The DNA was stored after eluting in Buffer AE by placing it at $-20^{\circ} \mathrm{C}$. ${ }^{[4]}$

Microwave Method: $200 \mu \mathrm{l}$ of digestion buffer (1M NaCl; $1 \mathrm{M}$ Tris -HCl, pH8; 0.5M EDTA, pH 8; $10 \%$ Sodium Dodecyl Sulphate) was added to the tissue sections and was subjected to high power microwave 
irradiation for 1.5 minutes for deparaffinisation. This technique was xylene free. Irradiation time was split into 15 segments to prevent over boiling. Centrifugation for 10 minutes at room temperature was done. The paraffin wax ring formed above the buffer was removed. Tissue pellet was digested in $200 \mu$ l digestion buffer containing $200 \mu \mathrm{l} / \mathrm{ml}$ Proteinase $\mathrm{K}$ at $56^{\circ} \mathrm{C}$ overnight. Centrifugation at room temperature at $8000 \mathrm{rpm}$ for 5 minutes was done. Supernatant containing DNA was collected in a separate tube. It was boiled for 10 minutes at $95^{\circ} \mathrm{C}$ to denature proteinase and proteins. DNA present in the supernatant was precipitated using the salting out method. ${ }^{[5]}$

Evaluation Of Extracted DNA: Yield of DNA and electrophoretic pattern: For each extraction method, the DNA purity was calculated using the A260/A280 ratio with a spectrophotometer (Eppendorf Bio Spectrometer). DNA yield was calculated using A260. ${ }^{[6]}$

Polymerase chain reaction: The DNA isolated using the three method was used for amplification of a 196bp fragment of p53 gene. Quantitative RT-PCR was performed with the Stratagene MX3000P (Agilent technologie). The double standard DNA-binding dye SYBRGreenI(KAPASYBRFASTqPCRKit)andprimers for $p 53$ (Forward: 5'-CTTGCCACAGGTCTCCCC-3' and Reverse: 5'-GCCACTTGCCACCCTGCACA-3') were used. Amplification conditions were 30 seconds at $95^{\circ} \mathrm{C}, 30$ secs at $60^{\circ} \mathrm{C}$ and 30 secs at $75^{\circ} \mathrm{C}$ for 35 cycles.

The amplified PCR products were visualised using a gel electrophoresis with standard $2.0 \%$ agarose gel containing ethidium bromide stain under ultraviolet light. The optical densities of the electrophoretic bands were determined using Quantity One software. ${ }^{[6]}$
Statistical Analysis: The values of DNA yield and purity obtained using the three DNA extraction method for the three sample groups (Group A, B and C) were statistically analysed using the software Statistical Package for Social Sciences (SPSS), IBM Corp., Version 16. The level of significance was calculated by ANOVA test and Tukey test (for multiple comparison). Probability value ( $p$ value) less than 0.05 was considered statistically significant.

\section{Results}

All the three DNA extraction method provided a yield of DNA above $3 \mu \mathrm{g}$ which was considered to be good and were of adequate amount to perform PCR reaction. (Table 1) On multiple comparison of mean DNA yield obtained from the three different method, the difference in the DNA yield was statistically significant among all the three method ( $p$ value $<0.05$ ) in group A and the difference in the DNA yield between kit method and microwave oven method was not statistically significant ( $p$ value $>0.05$ ) in Groups B and C. (Table 2) The average purity of DNA obtained using the three method were within the range of 1.7 to 2.0. There was no statistical difference in the average purity among the three method ( $p$ value $>0.05$ ). (Table 1) On multiple comparison of mean DNA purity obtained from the three different groups using the kit method, the difference in DNA purity was statistically significant only between Groups A and C. (Table 3) However, a comparison of DNA quantity among the groups was not possible as standardization of the tissue samples by weight was not done.

Table 1: Mean DNA yield and purity obtained using the three DNA extraction method from the three groups.

\begin{tabular}{|l|c|c|c|c|c|c|}
\hline & \multicolumn{2}{|c|}{ Group A } & \multicolumn{2}{c|}{ Group B } & \multicolumn{2}{c|}{ Group C } \\
\hline & $\begin{array}{c}\text { Mean DNA } \\
\text { Yield } \pm \text { S.D( } \boldsymbol{\mu g})\end{array}$ & $\begin{array}{c}\text { Mean DNA } \\
\text { Purity } \pm \text { S.D }\end{array}$ & $\begin{array}{c}\text { Mean DNA } \\
\text { Yield } \pm \text { S.D }(\boldsymbol{\mu g})\end{array}$ & $\begin{array}{c}\text { Mean DNA } \\
\text { Purity } \pm \text { S.D }\end{array}$ & $\begin{array}{c}\text { Mean DNA } \\
\text { Yield } \pm \text { S.D }(\boldsymbol{\mu g})\end{array}$ & $\begin{array}{c}\text { Mean DNA } \\
\text { Purity } \pm \text { S.D }\end{array}$ \\
\hline Salting out & $59.07 \pm 9.73$ & $1.76 \pm 0.63$ & $36.93 \pm 6.16$ & $1.75 \pm 0.18$ & $28.60 \pm 6.35$ & $1.78 \pm 0.22$ \\
\hline Kit & $20.99 \pm 2.89$ & $1.89 \pm 0.15$ & $13.72 \pm 2.94$ & $1.76 \pm 0.15$ & $10.75 \pm 1.04$ & $1.72 \pm 0.15$ \\
\hline Microwave & $12.37 \pm 1.43$ & $1.89 \pm 0.20$ & $9.09 \pm 1.08$ & $1.71 \pm 0.20$ & $7.46 \pm 1.50$ & $1.71 \pm 0.18$ \\
\hline$P$ value (ANOVA) & 0.000 & 0.092 & 0.000 & 0.807 & 0.000 & 0.687 \\
\hline
\end{tabular}

$P$ value $<0.05$ is significant; S.D: Standard Deviation 
Table 2: Multiple comparison of mean DNA yield and purity among different extraction method in Groups $A, B$ and $C$.

\begin{tabular}{|l|l|c|c|c|c|c|c|}
\hline \multirow{2}{*}{$\begin{array}{l}\text { Method)- } \\
\text { Comparison }\end{array}$} & \multicolumn{2}{|c|}{ Group A (P value) } & \multicolumn{2}{c|}{ Group B (P value) } & \multicolumn{2}{c|}{ Group C (P value) } \\
\cline { 3 - 8 } & DNA Yield & DNA Purity & DNA Yield & DNA Purity & \multicolumn{2}{c|}{ DNA Yield } & DNA Purity \\
\hline \multirow{3}{*}{ Salting Out } & Kit & 0.000 & 0.134 & 0.000 & 0.995 & 0.000 & 0.784 \\
\cline { 2 - 8 } & Microwave & 0.000 & 0.141 & 0.000 & 0.865 & 0.000 & 0.664 \\
\hline \multirow{2}{*}{ Kit } & Salting out & 0.000 & 0.134 & 0.000 & 0.995 & 0.000 & 0.784 \\
\cline { 2 - 8 } & Microwave & 0.008 & 1.000 & 0.039 & 0.814 & 0.015 & 0.987 \\
\hline \multirow{2}{*}{ Microwave } & Salting out & 0.000 & 0.141 & 0.000 & 0.865 & 0.000 & 0.694 \\
\cline { 2 - 8 } & Kit & 0.008 & 1.000 & 0.039 & 0.814 & 0.015 & 0.987 \\
\hline
\end{tabular}

$P$ value $<0.05$ is significant; S.D: Standard Deviation

Table 3: Multiple comparison of mean DNA purity among three different groups in kit method

\begin{tabular}{|l|c|}
\hline Groups (Comparison) & P value \\
\hline Group A vs Group B & 0.14 \\
\hline Group A vs Group C & 0.05 \\
\hline Group B vs Group C & 0.87 \\
\hline
\end{tabular}

$P$ value $<0.05$ is significant

DNA extracted from the three method in all three groups was assessed for amplification of $196 \mathrm{bp}$ fragment of p53 gene by real time PCR. All the samples of extracted DNA from the three method belonging to Group A, B and C showed successful amplification.
The amplified PCR products were analysed by electrophoresis on $2.0 \%$ agarose gel with ethidium bromide staining viewed under UV light. A band was noted at the level of $196 \mathrm{bp}$ in comparison with the DNA ladder indicating successful amplification. However, variation in the intensity of the bands was noticed. The intensity of bands in gel electrophoresis is proportional to the amount of amplifiable DNA. (Figure 1) In the present study, the kit method showed no statistical difference in the mean optical density units among the three groups. (Table 4) The salting out and microwave method showed a statistical difference in Groups A and $\mathrm{B}$ and also in Groups A and C. (Table 5).

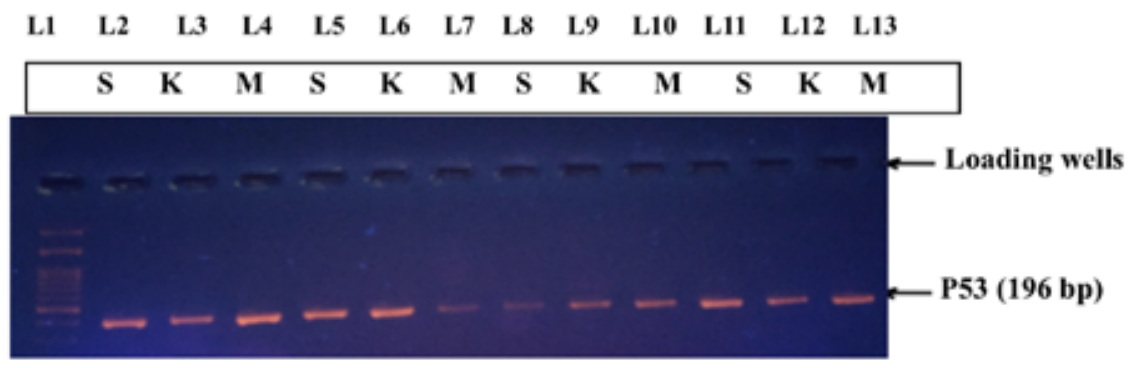
L1: 100 bp DNA Ladder
S-Salting out method
K - Kit method
L2-L13: Samples
M-Microwave oven method

Figure 1: Amplified 196 bp fragment of p53 on gel electrophoresis by all three extraction method

Table 4: Mean optical density units in Groups A, B and C

\begin{tabular}{|l|c|c|c|}
\hline Groups & Mean O.D \pm S.D (Salting Out) & Mean O.D \pm S.D (Kit) & Mean O.D \pm S.D (Microwave) \\
\hline A & $8129 \pm 653.3$ & $8664 \pm 1534.7$ & $7415 \pm 925.7$ \\
\hline B & $6423 \pm 656.9$ & $8117 \pm 496.15$ & $6038 \pm 999.6$ \\
\hline C & $5802 \pm 597.5$ & $7778 \pm 531.0$ & $5408 \pm 631.9$ \\
\hline$(P$ value $)$ & 0.000 & 0.145 & 0.000 \\
\hline
\end{tabular}

$P$ value $<0.05$ is significant; O.D: Optical Density, S.D: Standard Deviation 
Table 5: Multiple comparison of mean optical density units in Salting out and microwave oven method

\begin{tabular}{|l|c|c|}
\hline Groups (Comparison) & $\begin{array}{c}\text { Salting Out } \\
(\boldsymbol{P} \text { value) }\end{array}$ & $\begin{array}{c}\text { Microwave } \\
(\boldsymbol{P} \text { value })\end{array}$ \\
\hline Group A vs Group B & 0.004 & 0.000 \\
\hline Group A vs Group C & 0.000 & 0.000 \\
\hline Group B vs Group C & 0.253 & 0.093 \\
\hline
\end{tabular}

$P$ value $<0.05$ is significant

\section{Discussion}

The nature of genetic alterations occurring in the cells may be responsible for the clinical behaviour of tumours. Hence, examination of DNA from various tumours is necessary to correlate alterations in the genetic setup clinically and histologically and also to study various biomarkers that can be used in prognosis and targeted therapies or personalised medicine for tumours. Since extraction of DNA from fresh samples of similar tumours at a time may be practically difficult, many attempts have been made to extract DNA from stored formalin fixed paraffin embedded tissues that were previously prepared for routine histopathological examination. The present study was one such attempt to check the possibility of genomic DNA extraction from archival retrieved paraffin embedded tissue blocks. There are many physical and chemical factors (incubation time, temperature and materials used for extraction process, etc.) that affect the extraction of DNA from these tissues which subsequently affects further analytical procedures. Therefore it is essential to choose a suitable method from a wide range of protocols for efficient genomic DNA extraction with sufficient yield and purity. It should ideally be simple, reliable and cost effective. ${ }^{[7]}$

In the present study, the average yield of DNA from all the three study groups using the three extraction method was greater than $3 \mu \mathrm{g}$. According to W. Tang et al, 2009, DNA yield of 1 to $3 \mu \mathrm{g}$ from three $5 \mu \mathrm{m}$ sections was considered typically good. ${ }^{8}$ Rivero et al, 2006 and Mirmomeni et al, 2010 obtained significant DNA yield of more than $3 \mu \mathrm{g}$ using kit method (11-14 $\mu \mathrm{g}$ and 7.5$69 \mu \mathrm{g})$ and salting out method $(8-31 \mu \mathrm{g}$ and $6.5-93 \mu \mathrm{g})$ from FFPE tissues respectively. ${ }^{[4,6]}$

In Groups A, B and C, maximum DNA yield $(\mu \mathrm{g})$ was obtained using the salting out method followed by the kit and microwave oven method. Salting out method compared to other method yielded maximum DNA in all the three groups. Kit and microwave method of DNA extraction yielded similar amount of DNA in Groups B and C whereas in Group A, kit method yielded more DNA compared to the microwave method. In the present study, least DNA yield was observed in samples extracted using the microwave oven extraction method (12.37 $\mu \mathrm{g}, 9.09 \mu \mathrm{g}$ and $7.46 \mu \mathrm{g})$. This was contrary to Sato et al (2001), who observed mean DNA yield of $76 \mu \mathrm{g}$ in microwave method compared to other method. ${ }^{[9]}$ This reduction in DNA yield using microwave extraction in the present study could have resulted due to an extra purification step that was performed to eliminate the reagent SDS (Sodium Dodecyl Sulphate) which is a potent inhibitor of PCR as proposed by Gelfand et al. ${ }^{[10]}$ As per Sato et al, 2001, better DNA yield in his study using the microwave oven method might be due to lesser DNA loss attributed to less number of changes from the micro centrifuge tubes. ${ }^{[9]}$

In the present study, Salting out method showed significantly higher yield in comparison with the microwave and commercial kit method. Isola $\mathrm{J}$ et al, 1994 found that prolonged incubation time improved total DNA yield greatly compared to shorter incubation periods. This is applicable to the present study, as salting out method had a prolonged incubation time (3 days) compared to the kit ( 3 hours) and microwave method (overnight). ${ }^{[11]}$

The values of DNA purity obtained in the present study were within the range of 1.7 to 2.0 which was suggestive of 'clean DNA' according to Mirmomeni et al, 2010 who had obtained DNA of purity in a range of 1.66 to $1.97 .{ }^{[6]}$ DNA of acceptable purity was obtained in all the three method which was in contrast to the study by Watanabe et al, 2017, where the kit method provided DNA of better purity when compared to the other method. ${ }^{[12]}$

The assessment of successful DNA extraction using the three method from the three sample groups was confirmed by a PCR amplification of 196 bp fragment of p53 gene. The genomic DNA obtained from all the samples were efficiently amplified. The intensity of the bands formed after gel electrophoresis of the PCR products denote that the amplifiable DNA was higher in the samples extracted using the kit method although the yield was maximum in the salting out method. This is in accordance with Gilbert et al, 2007, who observed that the total DNA content does not essentially represent 
the quantity of DNA that is amplifiable by PCR. Also, the increased nucleic acid - protein cross link reversal properties of the components in the kit extraction buffers when compared to the conventional buffers yield higher levels of PCR amplifiable DNA by kit method. ${ }^{[13]}$

Studies by Shi et al, 2004 and Sato et al, 2005 suggested that reduction in the DNA manipulations can be done in order to improve the efficiency of PCR by avoiding few steps used in the regular extraction protocol. However, the purity of the DNA obtained may be compromised. ${ }^{[14,9]}$ Though the kit method had minimal DNA manipulation, DNA of acceptable purity was obtained in the salting out and microwave method also.

The comparison of mean optical densities of the PCR products suggested that the amount of DNA that can be successfully amplified reduced progressively with longer duration of storage of the FFPE samples. This was in accordance with a study by Liborio et al, 2005, who observed a linear decrease in the number of successful amplifications with an increase in storage duration from FFPE tissues stored over a period of up to 40 years. This was due to the presence of high concentration of small DNA fragments which compete with the template DNA leading to very low or absence of amplification. ${ }^{[7]}$

\section{Conclusion}

In the present study, though the DNA yield was compared among the three different method within the groups, we were unable to compare DNA yield among the three different study groups as the standardisation of samples by weight was not done. Salting out method yielded the maximum amount of DNA compared to the other method in all the three groups. The purity of the extracted DNA was similar by all the three method in all the three groups and within the established range of clean DNA. The amount of amplifiable DNA fragments were found to be reduced with an increase in the storage time. Though commercial kit is a rapid method for DNA extraction, it is expensive. As an alternative, other method like salting out method can be tried for DNA extraction from paraffin embedded tissue samples as it is less expensive. Improved technical measures to enhance the amount of amplifiable DNA from salting out and microwave oven method are necessary.

\section{Ethical Clearance: Nil}

Source of Funding: Meenakshi Academy of Higher Education and Research, Chennai, India.

\section{Conflict of Interest: Nil}

\section{References}

1. Chacon-Cortes D, Griffiths LR. Method for extracting genomic DNA from whole blood samples: current perspectives. J Biorepos Sci Appl Med 2014;2:1-9.

2. Anandika Dhaliwal. DNA Extraction and Purification. Mater Method 2013;3:191.

3. Kumar D, Panigrahi MK, Suryavanshi M, Mehta A, Saikia KK. Quantification of DNA Extracted from Formalin Fixed Paraffin-Embeded Tissue Comparison of Three Techniques: Effect on PCR Efficiency. JCDR 2016;10(9):BC01-BC03.

4. Rivero ER, Neves AC, Silva-Valenzuela MG, Sousa SO, Nunes FD: Simple salting-out method for DNA extraction from formalin-fixed, paraffinembedded tissues. Pathol Res Pract. 2006;202: 523-9.

5. PKS Chan, DPC Chan, KF To, MY Yu, JLK Cheung, AF Cheng. Evaluation of extraction method from paraffin wax embedded tissues for PCR amplification of human and viral DNA. J Clin Pathol 2001;54:401-3.

6. Mirmoneni MH, Sajjadimajd S, Sisakhtnezhad S, Doranegrad F. Comparison of the three method for DNA extraction from Paraffin embedded tissues. J Biol Sci 2010;10:261-6.

7. Liborio TN, Etges A, Neves AC, Mesquita RA, Nunes FD. Evaluation of genomic DNA extracted from formalin-fixed, paraffin-embedded oral samples archives for the past 40-years. J Bras Patol Med Lab 2005;41(6):405-10.

8. Tang W, David FB, Wilson MM, Barwick BG, Leyland-Jones BR, Bouzyk MM. DNA extraction from formalin-fixed, paraffin-embedded tissue. Cold Spring Harb Protoc 2009;2009(2):pdb. prot5138. doi:10.1101/pdb.prot5138

9. Sato Y, Sugie R, Tsuchiya B, Kameya T, Natori M, Mukai K. Comparison of the DNA extraction method for polymerase chain reaction amplification from formalin fixed and paraffin-embedded tissues. Diagn Mol Pathol 2001;10(4):265-71.

10. Gelfand DH. Taq DNA polymerase. in: Erlich H. PCR Technology: Principles and Applications of DNA Amplification. New York: Stockton Press, 1989. p 17-22. 
11. Isola J, De Vries S, Chu L, Ghazvini S, Waldman F. Analysis of changes in DNA sequence copy number by comparative genomic hybridization in archival paraffin-embedded tumour samples. Am J Path 1994;145:1301-8.

12. Watanabe M, Hashida S, Yamamoto H, Matsubara T, Ohtsuka T, Suzawa K, et al. Estimation of agerelated DNA degradation from formalin-fixed and paraffin-embedded tissue according to the extraction method. Experimental and Therapeutic Medicine 2017;14(3):2683-8.

13. Gilbert MT, Haselkorn T, Bunce M, Sanchez JJ, Lucas SB, Jewell LD, et al. The isolation of nucleic acids from fixed, paraffin-embedded tissues-which method are useful when? PLoS ONE. 2007;2:e537.

14. Shi SR, Datar R, Liu C, Wu L, Zhang Z, Cote RJ, et al. Histochem Cell Biol 2004;122: 211. 